\title{
Fracture Resistance of Upper Central Incisors with Different Endodontic Accesses Restored with Lithium Disilicate Partial Laminate Veneers
}

\author{
Hamit Serdar Cotert (D) \\ IIgin Akcay iD ${ }^{2}$ \\ Irem Cotert ${ }^{\prime}$ \\ Ece Altinova Hepdurgun ${ }^{3}$ \\ 'Department of Prosthodontics, Faculty \\ of Dentistry, Ege University, Bornova, \\ İzmir, Turkey; ${ }^{2}$ Department of \\ Endodontics, Faculty of Dentistry, Ege \\ University, Bornova, İzmir, Turkey; \\ ${ }^{3}$ Ministry of Health, Demirköprü Oral \& \\ Dental Health Center, İzmir, Turkey
}

Correspondence: Hamit Serdar Cotert Ege Üniversitesi, Diș Hekimliği Fakültesi, Protez A.D, Bornova, İzmir, 35100,

Turkey

Tel +902323880327

$\mathrm{Fax}+902323880325$

Email cotert@gmail.com
Purpose: A treatment protocol involving the root canal treatment with conventional palatal access cavity and the partial veneer application may considerably reduce the fracture resistance of the teeth. On the other hand, labial access cavity within the partial veneer outlines followed with the partial veneer application may more successfully recover the lost fracture resistance of the endodontically treated teeth. In this regard, the present study aims to compare the fracture resistances of upper central incisors endodontically treated with palatal and labial accesses and restored with restorative resin composite and lithium disilicate partial veneers.

Materials and Methods: Three groups consisting ten specimens each were prepared by using extracted sound human upper central incisors. Root canal treatments with palatal access, resin composite restoration of the access cavities and veneer restorations were applied to the first group (Group P). Root canal treatments with labial access, resin composite restoration of the access cavities and veneer restorations was applied to the second group (Group L). Veneer restorations were applied to the third group (Group C) without root canal treatment. Specimens were thermocycled and loaded to fracture in order to record their fracture resistances.

Results: The mean fracture resistance of Group $\mathrm{C}$ was observed to be significantly higher, compared to Groups $\mathrm{P}$ and L $(\mathrm{P}<0.05)$. Fracture resistance of Group L was observed to be higher, compared to Group P, but the difference was not found statistically significant. Light microscope revealed that the specimens fractured in five different modes.

Conclusion: Although the mean fracture resistance of the teeth that endodontically treated with labial access cavity prior to the ceramic partial veneer application was higher in comparison with the teeth that endodontically treated with palatal access cavity prior to the ceramic partial veneer application, the difference was found statistically insignificant $(\mathrm{P}<0.05)$.

Keywords: access cavity, palatal access, labial access, partial veneer, laminate veneer, fracture resistance

\section{Introduction}

A successful root canal treatment requires the removal of infection from the root canal system and the conservation of the remaining dental tissue using direct or indirect restorations. ${ }^{1}$ Long-term success relies on the protection of the root canal cavity from re-infection and proper distribution of the occlusal forces on the remaining tooth structure. ${ }^{1}$

It is known that the greatest challenges facing the operator during root canal treatment are the preparation of the access cavity and its proper restoration. ${ }^{2}$ The importance of the access cavity has been expressed in some studies as the "key to success", "access is success", 3 and "an opening for success". 4 Several studies have 
evaluated the properties of endodontic access cavities and described the same in detail. ${ }^{3-6}$ Conventional access cavity is generally not conservative, as it requires the removal of any dentine undercuts and pulp chamber ceiling that can hinder the visibility and access to the dental canal openings and cavity walls. Consequently, the technique may weaken the remaining tooth structure, especially in the cervical region, and can result in fractures. ${ }^{6,7}$ Previous literature has reported that access cavity is one of the most common causes of postendodontic tooth fracture. ${ }^{8-11}$

The most suitable access cavity configuration pertaining to the anterior teeth has been investigated. ${ }^{12-16}$ These studies comparatively evaluated the conventional cingulum access, incisive edge access, and the labial access. In some of these studies, the labial access cavity has been proposed as an alternative to the conventional cingulum access cavity in situations involving the teeth with anatomical or operative restrictions. ${ }^{13-15}$ Certain studies that involved anatomical evaluations have reported that the labial access cavity, which is to be opened in the labial direction, is more convenient, compared to the conventional cingulum approach, in order to effectively obtain access to the pulps of the upper or lower anterior teeth and to conserve more of the dentin tissue. ${ }^{17-20}$ In addition, it has been shown that the labial access cavity does not complicate or prevent the success of intra-canal operations. ${ }^{1}$

Previous literature states that the type of restoration that is to be applied after the root canal treatment, the material used, and the methods used for the restoration are important for the long-term success, and the bacterial sealing ability of the walls of the access cavity and the intermediate phase of restoration has been pointed out. ${ }^{21-24}$ After the completion of root canal treatment, restoration of the access cavity using glass ionomer cement (GIC) and resin composite is a well-known, conventional approach to complete the root canal treatment. ${ }^{25,26}$ GIC liner has been shown to reduce the cuspal deflection and microleakage. ${ }^{16}$

The use of full contour or partial ceramic restorations for the access cavities has attracted attention with successful results. ${ }^{27,28}$ Some studies have evaluated the fracture strength of the teeth that underwent root canal treatment prior to the restoration using ceramic partial veneers. ${ }^{27}$ The effects of partial veneer preparation types, and the various restorative protocols have been reported. ${ }^{29,30}$ Ceramic partial veneers are successfully used to correct several disorders that result in an unpleasant appearance with regard to the anterior dentition, thereby improving the esthetics. Both patients and practitioners prefer the aforementioned technique, owing to the following main reasons: Ceramic partial veneers are known to be conservative and offer high esthetic performance, high bond strength, and possess the ability to maintain these properties for a long time. ${ }^{31}$ Many esthetic disorders that warranted full contour crowns in the past can be resolved currently using the application of ceramic partial veneers. ${ }^{32-34}$

The esthetic and functional success of partial veneers led to extensive research and several studies have reported that many variables affect the clinical service duration and survival rates of the restorations. Examples of the aforementioned variables are discolorations, abrasions, diastemas, extension requirements (apical, incisal, or proximal), existing composite restorations, and tooth vitality. It has been reported that among the abutment teeth pertaining to ceramic partial veneers, the pulpless teeth exhibit more frequent coronal fractures compared to the vital teeth, and the difference was reported to be statistically significant. ${ }^{35-37}$

The fracture strength pertaining to pulpless teeth has been shown to be lower, compared to intact teeth, which can be attributed to the cumulative effect of the access cavity preparation and the mechanical cleaning and medication of the canals. ${ }^{38}$ But, the preparation of the access cavity within the partial veneer outline prior to the root canal treatment and subsequent veneer application may recover the fracture resistance of the tooth. Considering the results pertaining to the abovementioned studies, the present study aims to compare the fracture resistances of upper central incisors endodontically treated with palatal and labial accesses and restored with restorative resin composite and lithium disilicate partial veneers.

Null hypothesis was established as:

There is no difference between the fracture resistances of the teeth that underwent root canal treatment with palatal and labial access cavities prior to the application of ceramic partial veneers.

\section{Materials and Methods Specimen Preparation}

The present study was performed under the Ethics Board of Ege University Faculty of Medicine's approval number 15-10.1/1 and dated 29th December 2015 for the use of human tissue in the study. The patients whose teeth were used for this research had provided informed consent, in accordance with the Declaration of Helsinki. The current study involved 30 upper central incisors obtained from individuals between the ages of 30 and 55 years, owing 
to the periodontal reasons. The teeth involved in the current study did not exhibit any restorations, caries or fractures. Soft tissue and/or calculus residues were scraped off using periodontal curettes and the teeth were brushed using nonaromatic pumice. The cleaned teeth specimens were examined under a halogen light source using a magnifying glass. The teeth that displayed cracks were excluded. The teeth specimens were stored in distilled water at room temperature with a few thymol crystals until the canal treatments.

\section{Equilibration of the Test Groups}

The teeth specimens divided into three equilibrated groups containing ten specimens each. For this purpose, the teeth specimens were numbered and the numbers were inscribed on the corresponding root surface using a pencil. The mesio-distal $\left(\mathrm{d}_{\mathrm{m}-\mathrm{d}}\right)$ and labio-lingual root diameters $\left(\mathrm{d}_{1-1}\right)$ at the cemento-enamel junction and the anatomical crown length (h) pertaining to each sample were recorded. The aforementioned measurements were processed in accordance with the following correlation:

$$
\left(\mathrm{d}_{\mathrm{m}-\mathrm{d}}\right) \mathrm{X}\left(\mathrm{d}_{\mathrm{l}-1}\right) / \mathrm{h}=\mathrm{EV}
$$

and a corresponding equilibration value (EV) pertaining to each specimen was calculated. During the categorization of the sample teeth into the three test groups, care was taken to ensure that the average of the equilibration value in the test groups was the same.

The teeth specimen in the first group did not undergo any endodontic intervention. This group was designated as the control group (Group C). The teeth specimen in the second group underwent root canal treatment with the conventional palatal access cavity (Group P). The initial entrance was planned through the center of the palatal surface and the cingulum. Subsequently, conventional access cavity preparation was done. The teeth specimen in the third group underwent root canal treatment with the labial access cavity (Group L). During the procedure of access cavity preparation in this group, the bur was positioned parallel to the long axis of the tooth, in order to reach the pulp in a straight line, and applied to the center of the labial surface of the tooth. Both forms of the access cavities were prepared on the coronal side at the level of the cingulum and the pulp horns were removed in the mesio-distal direction. Ceramic partial veneers were applied to all the three groups.

\section{Root Canal Treatment}

The ISO \#10 size K-file was advanced through the root canal. The canal length was determined radiographically. The working length was calculated to be $1 \mathrm{~mm}$ shorter than the measured canal length. The root canals were prepared up to size 50 (F5) using the ProTaper (Dentsply, Maillefer, Ballaigues, Switzerland) rotary instrument system. During preparation, the application of each file was preceded by the irrigation of the canals using $2 \mathrm{~mL}$ of $2.5 \% \mathrm{NaOCL}$ (sodium hypochlorite). Moreover, the final irrigation was performed using $2 \mathrm{~mL} \mathrm{17 \%}$ ethylenediaminetetraacetic acid (EDTA), followed by $2 \mathrm{~mL} 2.5 \% \mathrm{NaOCl}$. The root canals were rinsed with saline and dried using paper points, in order to eliminate the chemical effects of the solutions used for irrigation. The root canals were obturated using the single cone technique by means of ProTaper F5 gutta-percha (Dentsply, Maillefer, Ballaigues, Switzerland) and AH Plus (Dentsply De Trey, Konstanz, Germany) sealer. The access cavities were restored using resin composite restorative material (Tetric N-Ceram, Ivoclar-Vivadent, Schaan, Liechtenstein). After obturation, the teeth were stored at $37^{\circ} \mathrm{C}$ in a $100 \%$ humid environment for 24 hours for the resin composite to polymerize completely.

\section{Embedding the Teeth Specimens in Acrylic Cylinders}

Roots of the teeth specimen were embedded in autopolymerizing acrylic resin (Imicryl, Konya, Turkey), up to $1 \mathrm{~mm}$ apical of the cemento-enamel junction. A special positioner has been designed by authors for this purpose.

Each tooth specimen was sticked to the positioner at the incisive edge using base plate wax, with its long axis perpendicular to the ground plane. The positioner was fixed to a pin fixator (Degussa, Rosbach, Germany). A plastic tube was filled with autopolymerizing acrylic resin that was mixed in accordance with the manufacturer's recommendations. The vertical arm of the pin fixator was lowered by means of the loosening the screw. The tooth specimen fixed at the end of the vertical arm of the pin fixator was embedded in the autopolymerizing resin, up to a depth of $1 \mathrm{~mm}$ apical to the cemento-enamel junction. The position of the tooth specimen in the acrylic cylinder was fixed by tightening the screw of the pin fixator. The tooth specimen was held in the aforementioned position until the completion of polymerization (Figure 1).

\section{Manufacturing and Luting of Veneers}

Laminate Veneer Preparation Set (LVS, Komet, Gebr. Brasseler GmbH \& Co. KG, Lemgo, Germany) was used in the tooth preparation. The depth of labial reduction was standardized using a depth guide bur. A mini-chamfer 


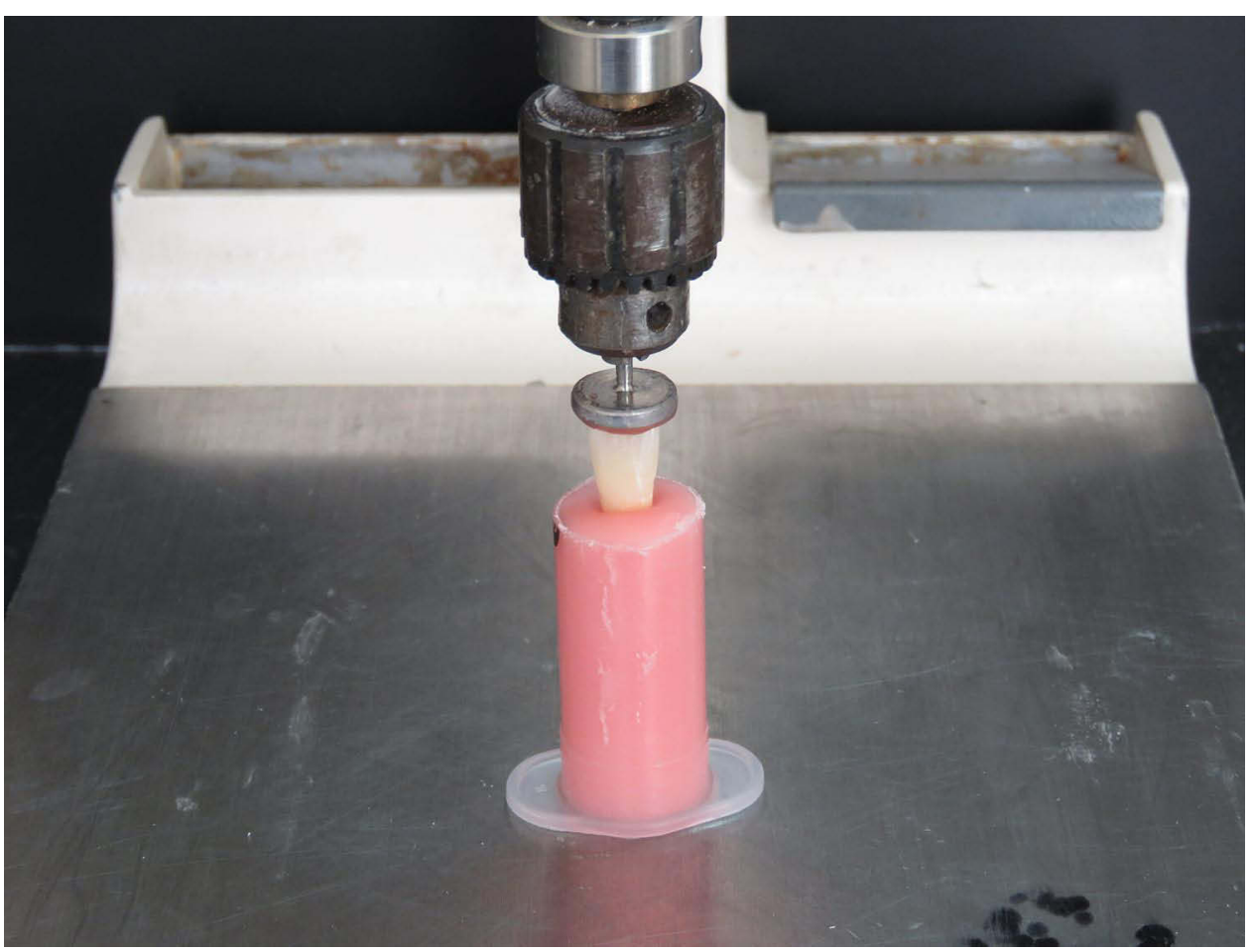

Figure I A specimen tooth embedded in autopolymerizing acrylic cylinder with the help of the vertical positioner.

shaped cervical finishing line was prepared on the enamel tissue. The mini-chamfer was extended towards the proximal contact points in the mesial and distal directions. However, the contact points were left intact. The incisal edge was prepared in an overlap design and the palatal finishing line was prepared as a mini-chamfer. The preparation was completed using a red-belt diamond finishing bur from the LVS. Impressions were made by means of plastic tubes and the polyether elastomeric impression material (Pentasoft DuoMix, 3M-ESPE, Seefeld, Germany). The master casts were made using type IV dental stone (Gilodur, Giulini Chemie, Ludwigshafen, Germany). The veneers were made by using heat-pressed lithium disilicate (LiDiSi) glass ceramic material (IPS E-Max Press, Ivoclar-Vivadent, Schaan, Liechtenstein) by means of conventional sandblasting, trimming, adjustments, glazing, and luting. Self-etch bond (AdheSE, Ivoclar-Vivadent, Schaan, Liechtenstein), 9.5\% hydrofluoric acid (Porcelain Etch, Ultradent, Salt Lake City, Utah, USA), silane (Silane, Ultradent, Salt Lake City, Utah, ABD), and a dual-polymerizing resin composite cement (Variolink Esthetic DC, Ivoclar-Vivadent, Schaan, Liechtenstein) have been used for luting procedures. Subsequent to the excess material was wiped clean, the cement was polymerized using a halogen light source (Optilux Demetron, Danbury, CT, USA) with an energy density of $480 \mathrm{~mW} / \mathrm{cm}^{2}$ for a duration of 40 seconds each from the palatal and labial directions. The entire finishing line was smoothed and polished using yellow-belt, diamond finishing burs (Komet, Gebr. Brasseler GmbH \& Co. KG, Lemgo, Germany), followed by polishing discs (Soflex Discs, 3M-ESPE, Seefeld, Germany).

\section{Thermal Cycling}

All the specimens underwent a thermal cycling process for 1000 cycles. The temperature ranged from $5^{\circ} \mathrm{C}$ to $55^{\circ} \mathrm{C}$ with a dwell time of 20 seconds. ${ }^{28}$ Subsequently, the fracture resistance of each specimen was evaluated.

\section{Load-to-Fracture Test}

In order to determine the fracture resistance, a force was applied to the palatal side $1 \mathrm{~mm}$ from of the incisive edge at in an angle of $45^{\circ}$ of the specimen using a special specimen holder. The specimens were placed in the housing on the specimen holder, fixed in the desired position by tightening the screw, and force was applied until fracture with a crosshead speed of $0.02 \mathrm{~mm} / \mathrm{min}$. The load pertaining to the failure in each specimen was recorded in $\mathrm{N}$ (Newton) (Shimadzu $\mathrm{KgN}$ 50, Shimadzu Corp., Kyoto, Japan) (Figure 2). The fractured surfaces were examined under a digital microscope (Leica S8 APO, Ernst-Leitz GmbH, Wetzlar, Germany) using the 


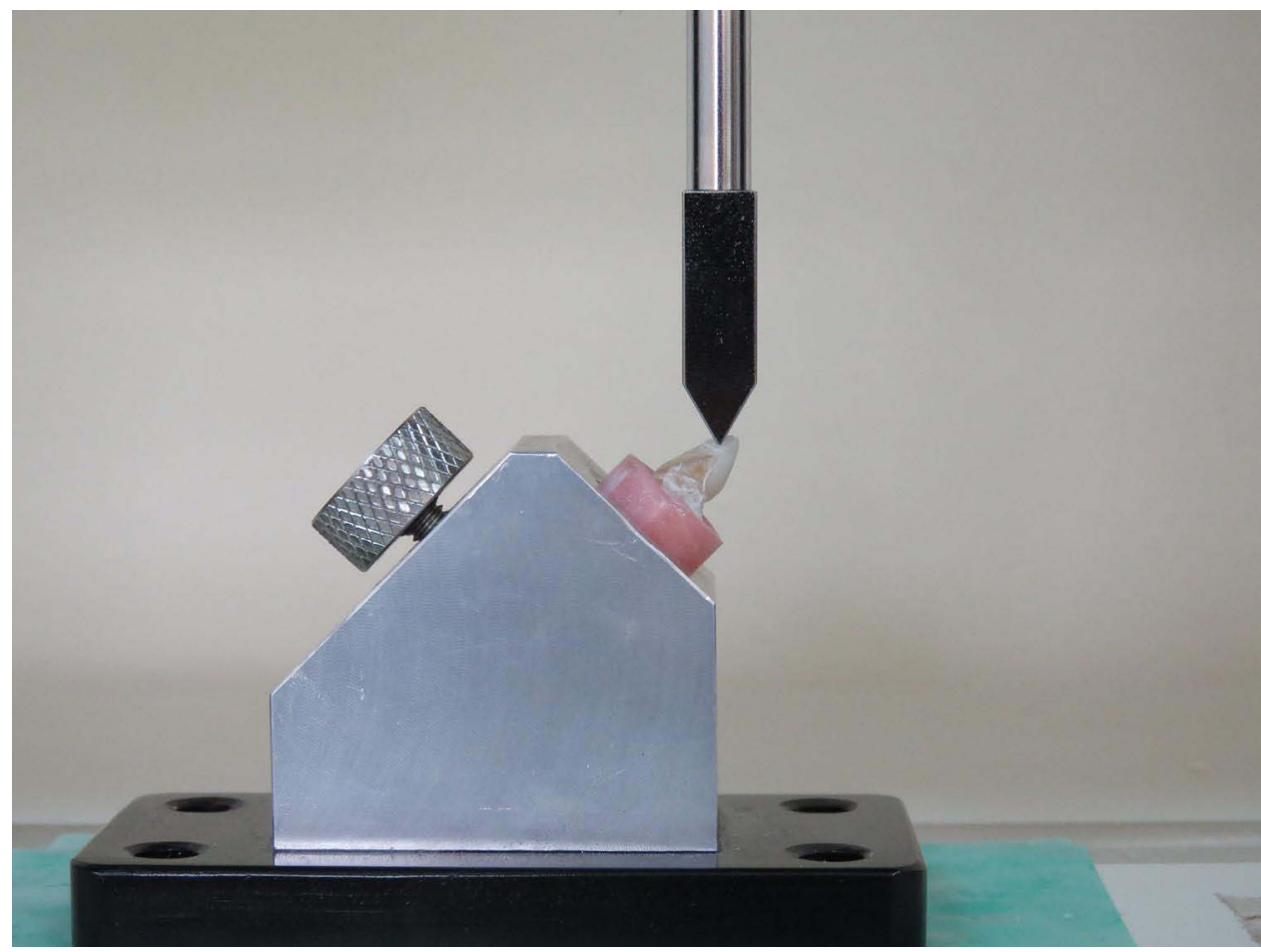

Figure 2 A specimen which is fixed in the housing of the special specimen holder, during fracture testing.

magnifications between $10 \mathrm{X}$ and 50X; the failure modes were recorded and photographs were taken (Leica DFC 295, ErnstLeitz GmbH, Wetzlar, Germany).

The current study performed the statistical analysis using the SPSS Statistics for Windows software (IBM Corp. Released 2017, IBM SPSS Statistics for Windows, Version 25.0, IBM Corp., Armonk, NY, USA). The Shapiro-Wilk test at a confidence interval of $95 \%$ showed that the normality of the data pertaining to the fracture strength is statistically significant and the data followed the normal distribution pattern.

\section{Results}

\section{Load-to-Fracture Test Results}

Descriptive statistics of the test groups are presented in Table 1. Accordingly, the lowest fracture resistance of 133 Ns was recorded in Group P and the highest 5245.3 Ns was recorded in Group C. The mean fracture resistances pertaining to the three groups $(\mathrm{C}, \mathrm{P}$ and $\mathrm{L})$ were estimated as 3122.6, 1867, and 2805.6 Ns, respectively (Figure 3). ANOVA revealed that the difference between the mean fracture resistances pertaining to the three groups was statistically significant $(\mathrm{P}<0.05$ ) (Table 2 ). Multiple comparisons performed by using the Bonferroni test, which revealed that the difference between the Groups $\mathrm{C}$ and
$\mathrm{P}$ was statistically significant, whereas the differences between the Groups $\mathrm{C}$ and $\mathrm{L}$ and the Groups $\mathrm{L}$ and $\mathrm{P}$ were not statistically significant $(\mathrm{P}<0.05)$ (Table 3 ).

\section{Failure Mode Analysis Results}

Distribution of the failure modes in the test groups is presented in Table 4. Microscopic examination of the fractured surfaces showed that the specimens exhibited five different failure modes. The first mode of failure is adhesive (AD) in nature; the failure occurred between the tooth and ceramic surfaces (Figure 4). No damage was detected in the tooth or the PLV. Adhesive mode of failure was observed in four specimens in Group $\mathrm{C}$ and two specimens in Group $\mathrm{P}$, whereas no adhesive failure was detected in Group L. The second type of fracture mode is cohesive and occurred only in veneer phase (CC). However, the tooth structure was not damaged. This type of failure mode was observed in one specimen in Group $\mathrm{C}$ and three specimens in Group L, but not observed in Group $P$ (Figure 5). In the third mode of failure, the cohesive failure occurred in both the tooth and the veneer (CCT) (Figure 6). One specimen each in the Groups $\mathrm{C}$ and $\mathrm{L}$ and three specimens in Group P displayed this third mode of failure. In the fourth mode of failure, the cohesive fracture occurred in the tooth while the ceramic was not damaged (CT). This kind of failure was detected in two specimens in Group C, five specimens in 
Table I Descriptive Statistics of the Test Groups

\begin{tabular}{|c|c|c|c|c|c|c|c|}
\hline & \multirow[b]{2}{*}{$\mathbf{N}$} & \multirow[b]{2}{*}{ Mean } & \multirow[b]{2}{*}{ Std. Dev. } & \multicolumn{2}{|c|}{ 95\% Confidence Interval For Mean } & \multirow[b]{2}{*}{ Minimum } & \multirow[b]{2}{*}{ Maximum } \\
\hline & & & & Lower Bound & Upper Bound & & \\
\hline $\mathrm{C}$ & 10 & 3122.680 & 1167.8090 & 2287.280 & 3958.080 & 1621.5 & 5245.3 \\
\hline$P$ & 10 & 1867.025 & 916.9602 & 1211.071 & 2522.979 & 133.0 & 2896.8 \\
\hline L & 10 & 2805.675 & 1061.6185 & 2046.239 & 3565.111 & 1674.5 & 5015.8 \\
\hline Total & 30 & 2598.460 & 1152.3898 & 2168.151 & 3028.769 & 133.0 & 5245.3 \\
\hline
\end{tabular}

Group P, and four specimens in Group L (Figure 7). The fifth mode of failure occurred as a root fracture (CR), wherein the sample tooth was fractured at the cervical region and no damage occurred in the coronal region of the tooth (Figure 8). Cervical fractures were observed in two specimens each in Groups $\mathrm{C}$ and $\mathrm{L}$, whereas the mode was not observed in Group P. Statistical analysis of the failure mode distribution in the test groups was made by using the Pearson Chi-Square test, which did not reveal a statistically significant difference, owing to the insufficient number of observations (Table 5).

\section{Discussion}

In the present study, the mean fracture resistances pertaining to the Groups $\mathrm{P}$ and $\mathrm{L}$, which underwent root canal treatment, were observed to be lower, compared to the control group (C), which was not treated endodontically. The difference was observed to be statistically significant $(\mathrm{P}<0.05)$. This finding is coherent with the reviewed literature. It is known that the fracture strength of the pulpless teeth is lower, compared to vital teeth, which can be attributed to the summative effect of the access cavity preparation, mechanical cleaning of the canals, and subsequent medication and various chemicals used in the medications. ${ }^{8-11,38}$ Tang et al reported that postendodontic fractures are caused by the stresses induced by operative interventions, such as the access cavity preparation, instrumentation, medication and obturation of the dental canal, post preparation, and coronal restoration. ${ }^{11}$

Although the fracture resistance values found for Group L were numerically higher compared to Group P,

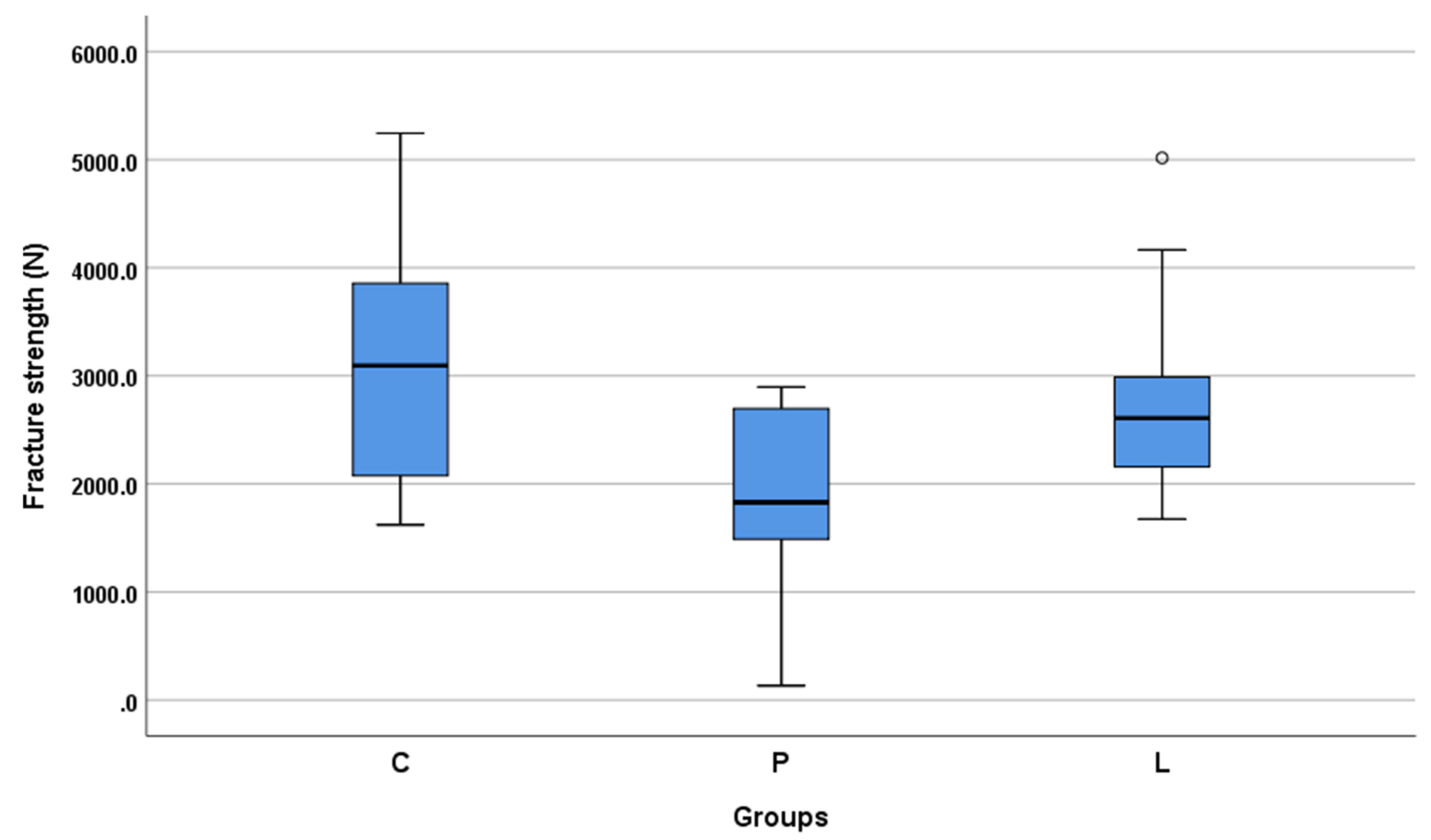

Figure 3 Bar graph presentation of the descriptive statistics. 
Table 2 The Difference Between the Mean Fracture Strengths of the Groups Was Statistically Significant According to One-Way ANOVA $(P<0.05)$

\begin{tabular}{|l|c|c|c|l|l|}
\hline & $\begin{array}{c}\text { Sum of } \\
\text { Squares }\end{array}$ & df & $\begin{array}{c}\text { Mean } \\
\text { Square }\end{array}$ & F & Sig. \\
\hline Between Groups & $8,527,418.238$ & 2 & $4,263,709.119$ & 3.839 & 0.034 \\
\hline Within Groups & $29,984,648.70$ & 27 & $1,110,542.545$ & & \\
\hline Total & $38,512,066.94$ & 29 & & & \\
\hline
\end{tabular}

no significant difference was observed between these groups $(\mathrm{P}<0.05)$. In view of the aforementioned findings, the current study accepted the null hypothesis.

Lingual access cavity is known as a traditional approach used in the root canal treatment of the anterior teeth. ${ }^{3-5,14}$ Labial access cavity is routinely recommended only in case of exceptions. ${ }^{14,15}$ Madjar et al determined the indications of the labial access cavity as: patients with limited mouth opening, Angle class II division II malocclusion, or using the Maryland bridge. ${ }^{15}$ Some authors advised that the labial access cavity particularly for the lower incisors. ${ }^{13}$ It has been reported that the access cavity prepared slightly buccal from the incisive edge provides access to the pulp canal in a straight line, thereby facilitating the root canal treatment and increasing its success. ${ }^{17,20}$ Most effective canal cleaning was found with the incisal access cavity that reaches the canal in a straight line in comparison with the conventional cingulum access. ${ }^{18}$ In addition; a root canal treatment with a labial access cavity restored with a partial veneer can be considered to conserve more tooth tissue and may recover the lost strength. Fracture strength of teeth that endodontically treated through palatal and labial access cavities was compared and reported that there was no statistically significant difference between the test groups with regard to the mean fracture resistance. ${ }^{19}$ Similarly, within the scope of the present study, the mean fracture resistance pertaining to Group L was greater than Group P, but the difference was not statistically significant $(\mathrm{P}<0.05)$.

Table 3 Multiple Comparisons with Bonferroni Test

\begin{tabular}{|c|c|c|c|c|c|c|}
\hline \multirow[b]{2}{*}{ (I) Group } & \multirow[b]{2}{*}{ (J) Group } & \multirow[b]{2}{*}{$\begin{array}{c}\text { Mean Difference } \\
(I-J)\end{array}$} & \multirow[b]{2}{*}{ Std. Error } & \multirow[b]{2}{*}{ Sig. } & \multicolumn{2}{|c|}{ 95\% Confidence Interval } \\
\hline & & & & & Lower Bound & Upper Bound \\
\hline \multirow[t]{2}{*}{ C } & $P$ & $1255.6550^{*}$ & 471.2839 & 0.039 & 52.722 & 2458.588 \\
\hline & L & 317.0050 & 471.2839 & 1.000 & -885.928 & 1519.938 \\
\hline \multirow[t]{2}{*}{$P$} & C & $-1255.6550 *$ & 471.2839 & 0.039 & -2458.588 & -52.722 \\
\hline & L & -938.6500 & 471.2839 & 0.170 & $-2|4| .583$ & 264.283 \\
\hline \multirow[t]{2}{*}{ L } & C & -317.0050 & 471.2839 & 1.000 & -1519.938 & 885.928 \\
\hline & $P$ & 938.6500 & 471.2839 & 0.170 & -264.283 & 2141.583 \\
\hline
\end{tabular}

Note: *The mean difference is significant at 0.05 level.

Table 4 Failure Modes and Their Distribution to the Groups

\begin{tabular}{|c|c|c|c|c|c|c|c|}
\hline & & \multicolumn{5}{|c|}{ Failure Modes } & \multirow[t]{2}{*}{ Total } \\
\hline & & AD & CC & ССT & CT & CR & \\
\hline C & $\begin{array}{l}\text { Count } \\
\% \text { within test group }\end{array}$ & $\begin{array}{l}4 \\
40.0 \%\end{array}$ & $\begin{array}{l}1 \\
10.0 \%\end{array}$ & $\begin{array}{l}1 \\
10.0 \%\end{array}$ & $\begin{array}{l}2 \\
20.0 \%\end{array}$ & $\begin{array}{l}2 \\
20.0 \%\end{array}$ & $\begin{array}{l}10 \\
100.0 \%\end{array}$ \\
\hline$P$ & $\begin{array}{l}\text { Count } \\
\% \text { within test group }\end{array}$ & $\begin{array}{l}2 \\
20.0 \%\end{array}$ & $\begin{array}{l}0 \\
0.0 \%\end{array}$ & $\begin{array}{l}3 \\
30.0 \%\end{array}$ & $\begin{array}{l}5 \\
50.0 \%\end{array}$ & $\begin{array}{l}0 \\
0.0 \%\end{array}$ & $\begin{array}{l}10 \\
100.0 \%\end{array}$ \\
\hline L & $\begin{array}{l}\text { Count } \\
\% \text { within test group }\end{array}$ & $\begin{array}{l}0 \\
0.0 \%\end{array}$ & $\begin{array}{l}3 \\
30.0 \%\end{array}$ & $\begin{array}{l}1 \\
10.0 \%\end{array}$ & $\begin{array}{l}4 \\
40.0 \%\end{array}$ & $\begin{array}{l}2 \\
20.0 \%\end{array}$ & $\begin{array}{l}10 \\
100.0 \%\end{array}$ \\
\hline Total & $\begin{array}{l}\text { Count } \\
\% \text { within test group }\end{array}$ & $\begin{array}{l}6 \\
20.0 \%\end{array}$ & $\begin{array}{l}4 \\
13.3 \%\end{array}$ & $\begin{array}{l}5 \\
16.7 \%\end{array}$ & $\begin{array}{l}11 \\
36.7 \%\end{array}$ & $\begin{array}{l}4 \\
13.3 \%\end{array}$ & $\begin{array}{l}30 \\
100.0 \%\end{array}$ \\
\hline
\end{tabular}




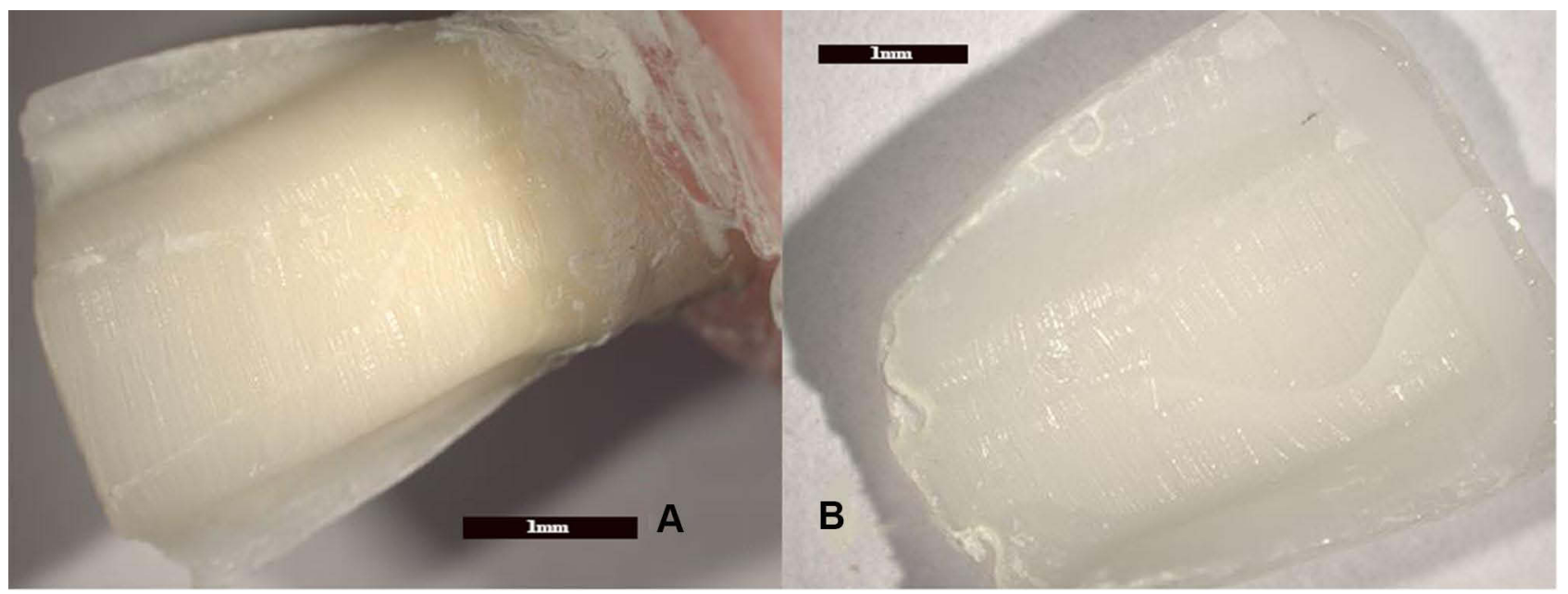

Figure 4 Adhesive failure between the tooth and ceramic surfaces. No damage was detected in the tooth (A) or the porcelain (B).

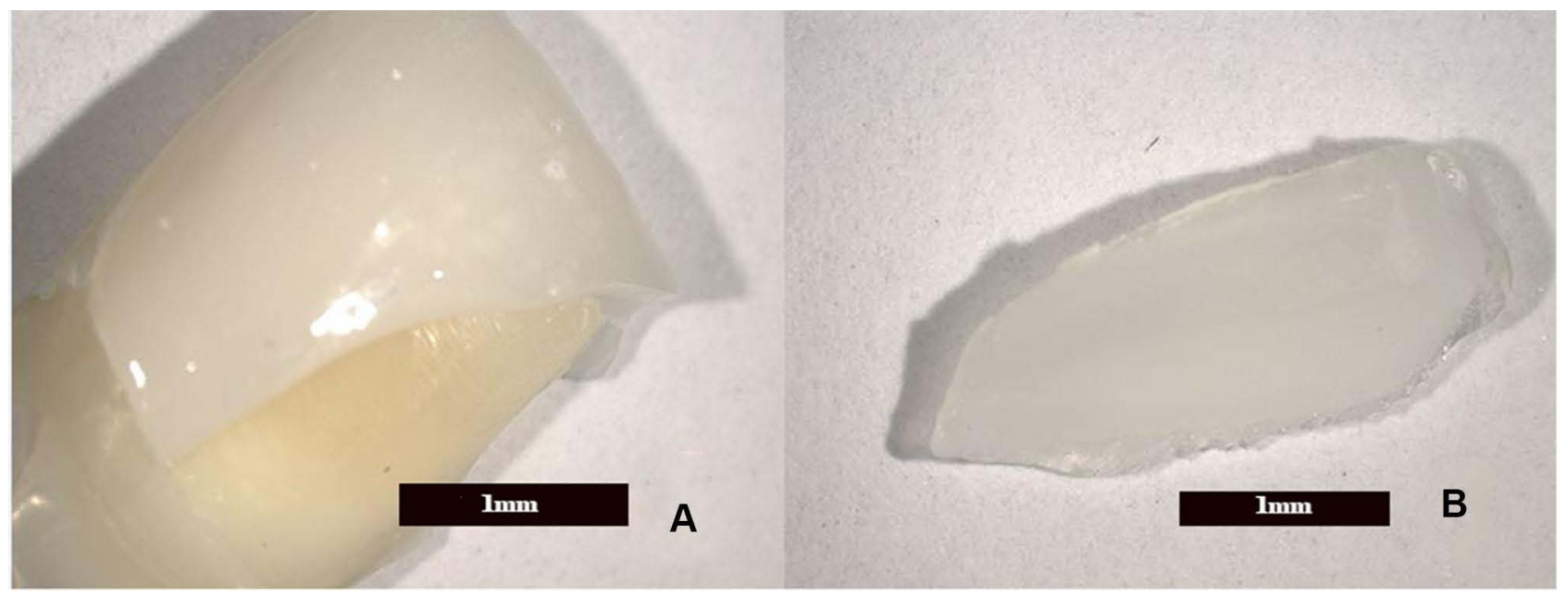

Figure 5 Cohesive failure in which the tooth structure is not damaged $(\mathbf{A})$, only the porcelain is fractured (B).

One of the methods that has been suggested to reduce the frequency of postendodontic fractures is the modification of the access cavity. Accordingly, the conservative access cavity, which is prepared in a narrower manner with direct orientation towards the root canal, is one of the most important components in the concept of MIE (minimally invasive endodontics). ${ }^{6,39,40}$ However, the application of MIE is excluded from the scope of present study.

According to Quilligan et al, long-term success of the root canal treatment relies on the protection of the root canal cavity from re-infection and proper distribution of the occlusal forces on the remaining tooth structure. ${ }^{1}$ Clark and Khademi stated that providing long-term structural integrity of the tooth is as important as the successful completion of the root canal treatment. ${ }^{8}$ Accordingly, the final restoration must be designed and planned prior to the commencement of the root canal treatment. Long-term permanence is related to the amount of remaining tooth structure and the quality of the coronal restoration after root canal treatment. Although some reports have recommended the application of crowns after root canal treatments to achieve this goal, adhesive ceramic partial restorations can provide a safer, more conservative and esthetic approach to accomplish the same objective. ${ }^{21}$ Some reports drew attention to the importance of coronal microleakage with regard to the prevention of re-infection and survival of the restoration. ${ }^{22-24}$ Restoration of endodontic access cavities with a combination of GIC and resin composite is a generally accepted, standard practice and it has been reported that such adhesive applications can overcome problems such as marginal leakage and 


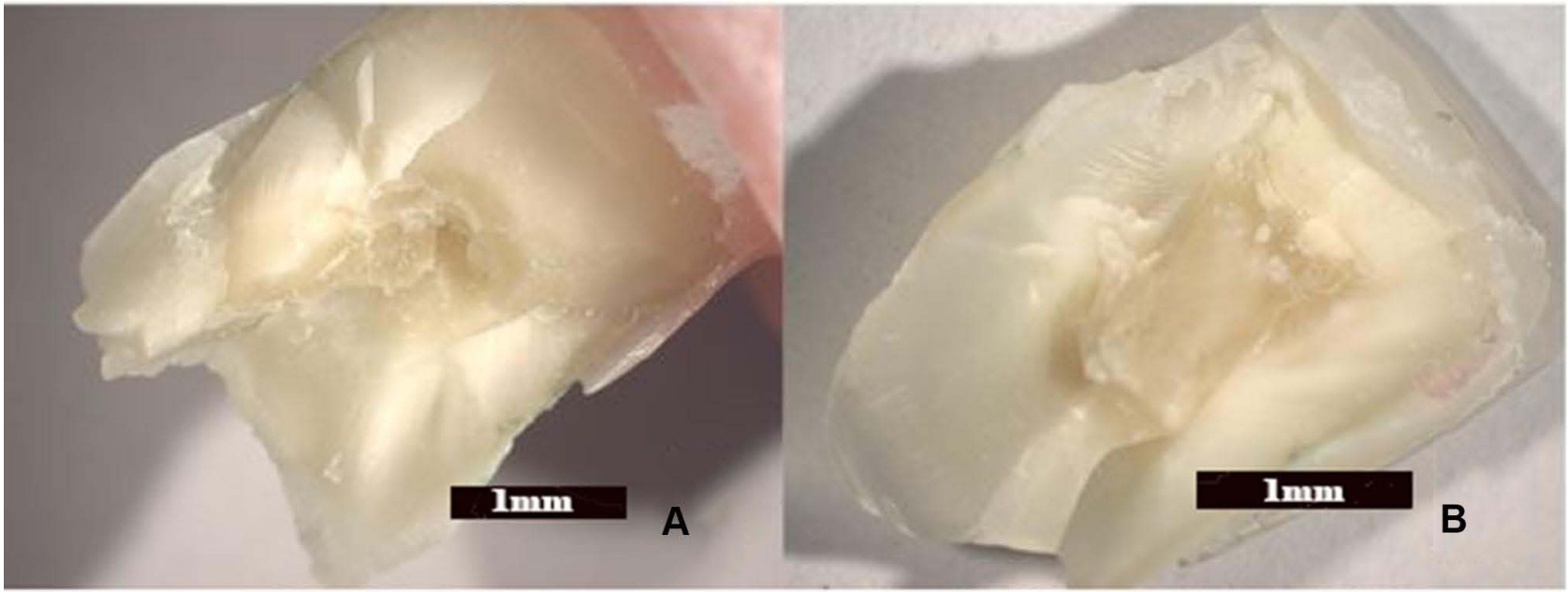

Figure 6 Cohesive failure in both the tooth (A) and the porcelain (B).

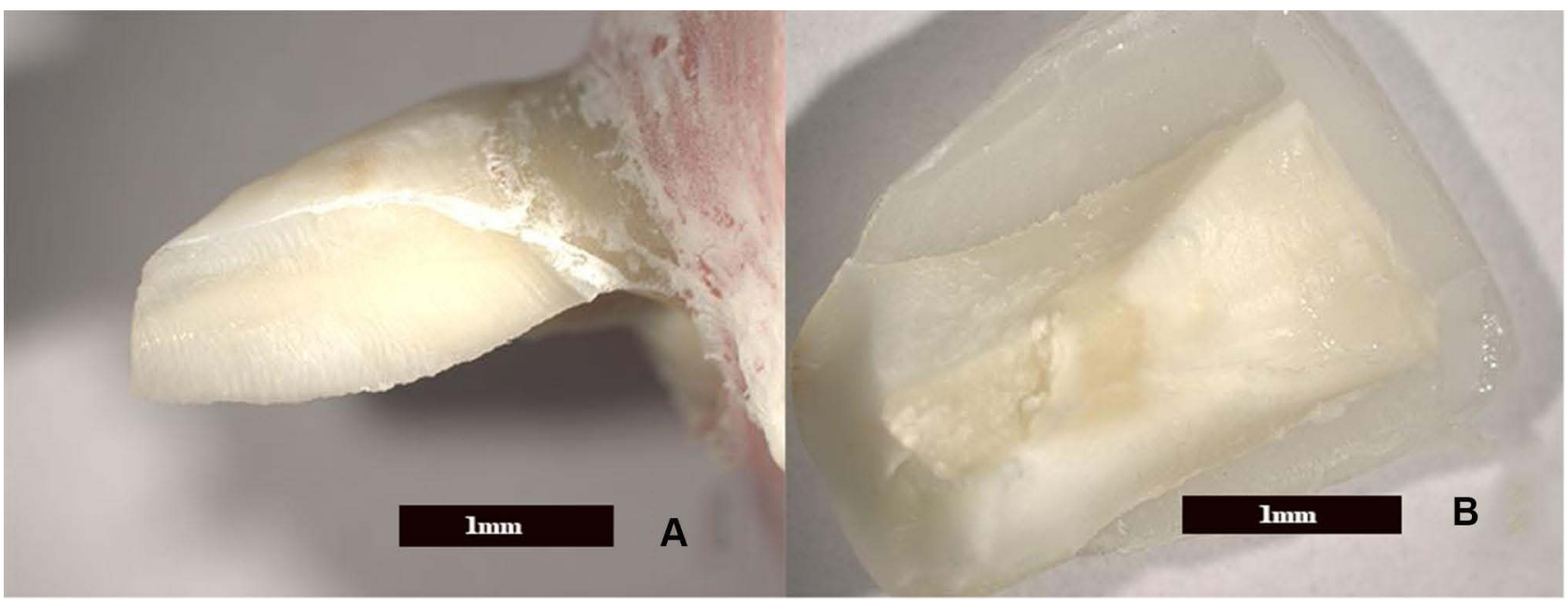

Figure 7 Cohesive failure in which the tooth structure is fractured $(\mathbf{A})$ while the porcelain was not damaged (B).

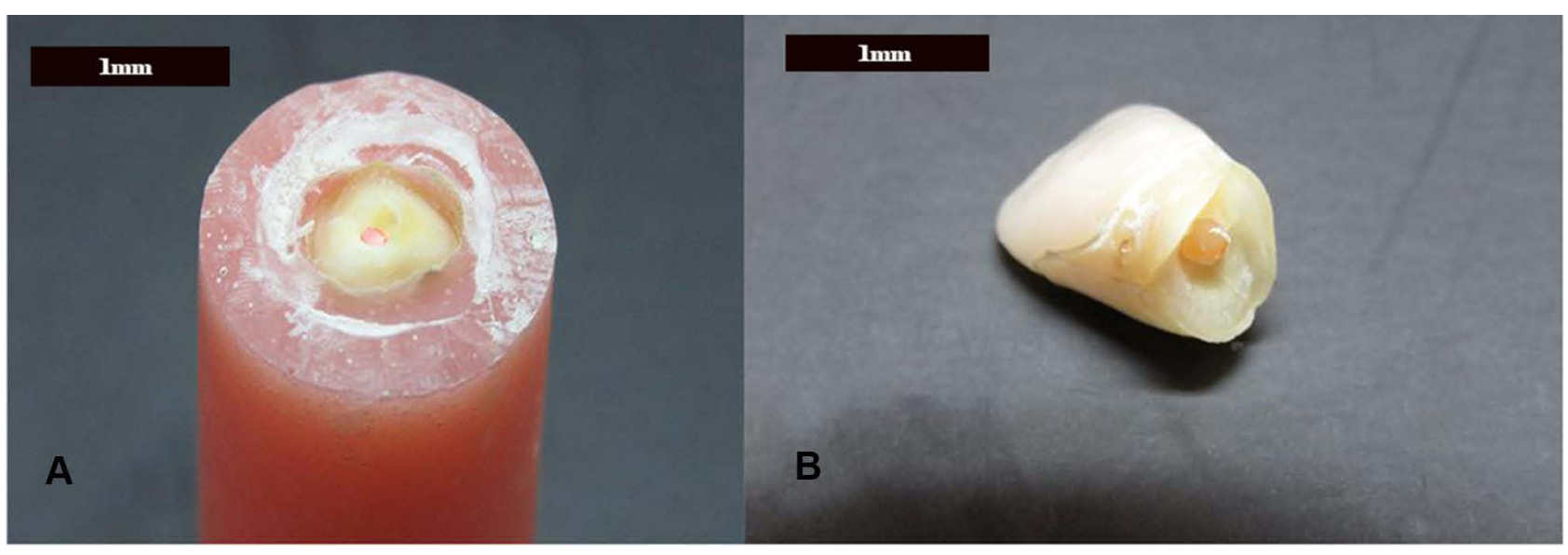

Figure 8 Cervical fracture as cohesive failure mode. Fractured root fragment of the specimen tooth (A) and coronal region with intact PLV (B). 
Table 5 Statistics of Failure Modes According to Pearson Chi Square

\begin{tabular}{|l|l|l|l|}
\hline & Value & df & Asymptotic Significance (2 Sided) \\
\hline Pearson Chi-Square & $12.373^{\mathrm{a}}$ & 8 & 0.135 \\
\hline Likelihood Ratio & 15.936 & 8 & 0.043 \\
\hline Linear-by-Linear Association & 1.697 & $\mathrm{I}$ & 0.193 \\
\hline N of Valid Cases & 30 & & \\
\hline
\end{tabular}

Notes: ${ }^{a} 15$ cells $(100.0 \%)$ have expected count less than 5 . The minimum expected count is 1.33 .

discoloration. ${ }^{25}$ Taha et al demonstrated that the removal of axial dentin, as a part of the access cavity preparation, resulted in an increase in the cuspal deflection and stresses, and the use of a GIC base reduced the stresses and leakage. ${ }^{16}$ It is known that the preparation of MOD (Mesio-Occluso-Distal) access cavities in the premolars results in reduced fracture strength of the remaining tooth structure and the increased possibility of cuspal fracture. ${ }^{26}$ According to Hannig et al, lost strength can be restored by the application of ceramic inlays. ${ }^{28}$ Reviewed literature also includes the studies that investigated the properties of anterior teeth that underwent both dental canal treatment and ceramic partial veneers. ${ }^{27,29,30}$ Several studies have investigated the service longevity of ceramic partial veneers and the prognostic variables that affected the same. ${ }^{35-37}$ Tooth vitality is one of these variables. Some studies have reported that pulpless teeth restored with ceramic partial veneers exhibit more frequent coronal fractures, compared to vital teeth, and the difference was statistically significant. ${ }^{35,36}$ Effect of root canal treatment on the deflection of the teeth that underwent restoration using indirect resin composite and ceramic partial veneers was also investigated with in-vitro studies. ${ }^{29,30}$ It was demonstrated that the partial veneer preparation procedures increases the deflection values pertaining to the anterior teeth, but does not affect the fracture strength. The authors deliberated that ceramic partial veneer is the most suitable restoration for endodontically treated teeth.

It is a well-known fact that the greatest challenge faced by the research involving the assessment of fracture strength is the equilibration of the test groups consisting of extracted natural human teeth. Tooth specimens are generally distributed to the test groups on the basis of their size for this purpose. However, the classification of natural teeth as large and small by visual inspection cannot provide a precise equilibration among the test groups. The application of the equilibration value used in the present study provided a more balanced distribution of tooth specimens among the test groups, thereby improving the reliability of the findings. In view of the fact that the application of an equilibration value that can be used in the evaluations has not been reported in previous literature, it can be regarded as a novel and useful method.

\section{Conclusion}

The results obtained within the limits of the present study are as follows:

Root canal treatment reduces the fracture strength of the tooth, regardless of the access cavity localization $(\mathrm{P}<0.05)$.

Fracture resistance of the teeth that endodontically treated with labial access cavity followed by the partial veneer application was found comparatively higher than the fracture resistance of the teeth endodontically treated with palatal access followed by the partial veneer. But the difference was not statistically significant $(\mathrm{P}<0.05)$.

Since the root canal treatments within the scope of the present study were performed through access cavities that provided direct access to the pulp canal, further studies are warranted to verify the possible effects of minimal invasive endodontics on the current results.

The application of equilibration value was found useful to balance the test groups consisting natural, extracted human teeth specimens.

\section{Disclosure}

The authors report no conflicts of interest in this work.

\section{References}

1. Quilligan G, McKenna G, Finbarr Allen P. The restorability assessment and endodontic access cavity interface. Dent Update. 2016;43:933-936. doi:10.12968/denu.2016.43.10.933

2. Patel S, Rhodes J. A practical guide to endodontic access cavity preparation in molar teeth. Br Dent J. 2007;203:133-140. doi:10.1038/bdj.2007.682 
3. Carrotte PV. Current practice in endodontics: 3. Access is success, and rubber dam is easy. Dent Update. 2000;27:436-440. doi:10.12968/denu.2000.27.9.436

4. Ruddle CJ. Access preparation endodontic: an opening for success. Dent Today. 2007;26:114,116-119.

5. Janik JM. Access cavity preparation. Dent Clin North Am. 1984;28:809-818.

6. Plotino G, Grande NM, Isufi A, et al. Fracture strength of endodontically treated teeth with different access cavity designs. $J$ Endod. 2017;43:995-1000. doi:10.1016/j.joen.2017.01.022

7. Jiang HW. Theory and practice of minimally invasive endodontics. Zhonghua Kou Qiang Yi Xue Za Zhi. 2016;51:460-464.

8. Clark D, Khademi J. Modern molar endodontic access and directed dentin conservation. Dent Clin North Am. 2010;54:249-273. doi:10.1016/j.cden.2010.01.001

9. Reeh ES, Messer HH, Douglas WH. Reduction in tooth stiffness as a result of endodontic and restorative procedures. $J$ Endod. 1989;15:512-516. doi:10.1016/S0099-2399(89)80191-8

10. Soares PV, Santos-Filho PCF, Queiroz EC, et al. Fracture resistance and stress distribution in endodontically treated maxillary premolars restored with composite resin. J Prosthodont. 2008;17:114-119. doi:10.1111/j.1532-849X.2007.00258.x

11. Tang $\mathrm{W}, \mathrm{Wu} \mathrm{Y}$, Smales RJ. Identifying and reducing risks for potential fractures in endodontically treated teeth. $J$ Endod. 2010;36:609-617. doi:10.1016/j.joen.2009.12.002

12. Castagnola M, Testori T, Badino M. Access cavity for endodontic treatment of anterior teeth. G Ital Endod. 1991;5:15-17.

13. Clements RE, Gilboe DB. Labial endodontic access opening for mandibular incisors: endodontic and restorative considerations. J Can Dent Assoc. 1991;57:587-589.

14. Lay LS, Lai WH, Chi CY, Wu CT. Access cavity preparation for mandibular incisors with suspected two canals. Zhonghua Ya Yi Xue Hui Za Zhi. 1989;8:21-26.

15. Madjar D, Kusner W, Shifman A. The labial endodontic access: a rational treatment approach in anterior teeth. J Prosthet Dent. 1989;61:317-320. doi:10.1016/0022-3913(89)90136-4

16. Taha NA, Palamara JE, Messer HH. Cuspal deflection, strain and microleakage of endodontically treated premolar teeth restored with direct resin composites. J Dent. 2009;37:724-730. doi:10.1016/j. jdent.2009.05.027

17. LaTurno SA, Zillich RM. Straight-line endodontic access to anterior teeth. Oral Surg Oral Med Oral Pathol. 1985;59:418-419. doi:10.1016/0030-4220(85)90069-6

18. Mannan G, Smallwood ER, Gulabivala K. Effect of access cavity location and design on degree and distribution of instrumented root canal surface in maxillary anterior teeth. Int Endod J. 2001;34:176-183. doi:10.1046/j.1365-2591.2001.00359.x

19. Nissan J, Zukerman O, Rosenfelder S, Barnea E, Shifman A. Effect of endodontic access type on the resistance to fracture of maxillary incisors. Quintessence Int. 2007;38:364-367.

20. Zillich RM, Jerome JK. Endodontic access to maxillary lateral incisors. Oral Surg Oral Med Oral Pathol. 1981;52:443-445. doi:10.1016/0030-4220(81)90347-9

21. Aquilino SA, Caplan DJ. Relationship between crown placement and the survival of endodontically treated teeth. J Prosthet Dent. 2002;87:256-263. doi:10.1067/mpr.2002.122014

22. Barkhordar RA, Kempler D. Microleakage of endodontic access cavities restored with composites. $J$ Calif Dent Assoc. 1997;25:215-218.

23. Gale MS. Coronal microleakage. Ann R Australas Coll Dent Surg. 2000;15:299-305.
24. Nikaido T, Takano Y, Sasafuchi Y, Burrow MF, Tagami J. Bond strengths to endodontically-treated teeth. Am J Dent. 1999;12:177-180.

25. Croll TP. Adhesive restoration of an endodontically treated incisor. Quintessence Int. 1993;24:319-322.

26. ElAyouti A, Serry MI, Geis-Gerstorfer J, Löst C. Influence of cusp coverage on the fracture resistance of premolars with endodontic access cavities. Int Endod J. 2011;44:543-549. doi:10.1111/j.13652591.2011.01859.x

27. D’Arcangelo C, De Angelis F, Vadini M, D’Amario M, Caputi S. Fracture resistance and deflection of pulpless anterior teeth restored with composite or porcelain veneers. J Endod. 2010;36:153-156. doi:10.1016/j.joen.2009.09.036

28. Hannig C, Westphal C, Becker K, Attin T. Fracture resistance of endodontically treated maxillary premolars restored with CAD/CAM ceramic inlays. J Prosthet Dent. 2005;94:342-349. doi:10.1016/j. prosdent.2005.08.004

29. D’Arcangelo C, De Angelis F, Vadini M, Zazzeroni S, Ciampoli C, D'Amario M. In vitro fracture resistance and deflection of pulpless teeth restored with fiber posts and prepared for veneers. J Endod. 2008;34:838-841. doi:10.1016/j.joen.2008.03.026

30. Magne P, Tan DT. Incisor compliance following operative procedures: a rapid 3-D finite element analysis using micro-CT data. $J$ Adhes Dent. 2008;10:49-56.

31. Bloom DR, Padayachy JN. Aesthetic changes with four anterior units. Br Dent J. 2006;200:135-138. doi:10.1038/sj.bdj.4813192

32. Freire A, Achegas LR. Porcelain laminate veneer on a highly discoloured tooth: a case report. J Can Dent Assoc. 2010;76:126.

33. Pena CE, Viotti RG, Dias WR, Santucci E, Rodriques JA, Reis AF. Esthetic rehabilitation of anterior conoid teeth: comprehensive approach for improved and predictable results. Eur J Esthet Dent. 2009;4:210-224.

34. Sadigpour L, Geramipanah F, Nikzad S. Fixed rehabilitation of an ACP PDI class III patient with amelogenesis imperfecta. $J \quad$ Prosthodont. 2009;18:64-70. doi:10.1111/j.1532849X.2008.00368.x

35. Beier US, Kapferer I, Burtscher D, Dumfahrt H. Clinical performance of porcelain laminate veneers for up to 20 years. Int J Prosthodont. 2012;25:79-85.

36. Çötert HS, Dündar M, Öztürk B. The effect of various preparation designs on the survival of porcelain laminate veneers. J Adhes Dent. 2009;11:405-411.

37. Gürel G, Sesma G, Calamita MA, Coachman C, Morimoto S. Influence of enamel preservation on failure rates of porcelain laminate veneers. Int J Periodontics Restorative Dent. 2013;33:31-39. doi:10.11607/prd.1488

38. Corsentino G, Pedullà E, Castelli L, et al. Influence of Access Cavity Preparation and Remaining Tooth Substance on Fracture Strength of Endodontically Treated Teeth. J Endod. 2018;44:1416-1421. doi:10.1016/j.joen.2018.05.012

39. Alovisi M, Pasqualini D, Musso E, et al. Influence of Contracted Endodontic Access on Root Canal Geometry: an In-Vitro Study. J Endod. 2018;44:614-620. doi:10.1016/j.joen.2017.11.010

40. Silva EJNL, Rover G, Belladonna FG, De-deus G, da Silveira Teixeira C, Da silva Fidalgo TK. Impact of contracted endodontic cavities on fracture resistance of endodontically treated teeth: a systematic review of in vitro studies. Clin Oral Investig. 2018;22:109-118. doi:10.1007/s00784-017-2268-y 


\section{Publish your work in this journal}

Clinical, Cosmetic and Investigational Dentistry is an international, peer-reviewed, open access, online journal focusing on the latest clinical and experimental research in dentistry with specific emphasis on cosmetic interventions. Innovative developments in dental materials, techniques and devices that improve outcomes and patient satisfaction and preference will be highlighted. The manuscript management system is completely online and includes a very quick and fair peer-review system, which is all easy to use. Visit http://www.dovepress.com/testimonials.php to read real quotes from published authors. 